\title{
Proposition for an Adapted Management Process to Evolve from an Unsupervised LCA of Complex Industrial Systems towards an Eco-Designing Organisation
}

\author{
François Cluzel $^{* 1,2}$, Bernard Yannou', Yann Leroy ${ }^{2}$, Dominique Millet ${ }^{3}$ \\ ${ }^{1}$ Alstom Grid, Power Electronics Massy, Massy, France \\ ${ }^{2}$ Ecole Centrale Paris, Laboratoire Genie Industriel, Chatenay-Malabry, France \\ ${ }^{3}$ Supmeca, Laboratoire d'Ingenierie des Systemes Mecaniques et Materiaux, Toulon, France
}

\begin{abstract}
The integration of environmental concerns into the product design process is not trivial when dealing with complex industrial systems. Actually, environmental assessment methodologies like Life Cycle Assessments (LCA) reach, in this case, methodological and organisational limits. More generally, the complexity inherent in the design process may put off eco-design initiatives from a lack of organisational management, methods and tools. In this paper, we propose a project management methodology to facilitate the integration of eco-design into the design process of complex industrial systems. This methodology is based on continuous improvement and a DMAIC process. It is then structured around precise team definition, precise milestones, deliverables and phases. A first stage ensures a reliable environmental assessment of the full system and the identification of environmental improvement projects. A second stage allows the independent execution of the most promising improvement projects. A first application is proposed on the Alstom Grid AC/DC conversion substations for the aluminium industry. A Life Cycle Assessment has been performed with limited resources and has provided rich findings and promising perspectives. It shows in particular that the best environmental configuration of such a complex industrial system depends on external parameters like the implantation site.
\end{abstract}

Key words: Eco-design, Life Cycle Assessment (LCA), Product-oriented environmental management, Lean Six Sigma, complex industrial system, AC/DC conversion substation.

\section{Introduction}

Eco-design has become a major concern for many large companies in the last decade. Dealing first with mass consumer goods, B-to-B firms are now concerned. The constantly evolving regulations framework (particularly in the European Union with the WEEE [1], RoHS [2], EuP [3] directives or the REACH regulation [4]) and highly competitive markets are pushing the most innovative complex industrial systems producers towards a proactive ecodesign approach. However, substantial limitations are slowing down this deployment in the design process of such systems. Characterised by their complex architectures, complex life cycles or large-scale scope, these systems cannot be considered as "classical" products. Actually performing a Life Cycle Assessment (LCA) on a large energy system is an extremely hard task and the lack of resources (people, time, money) as well as the lack of accurate data quickly becomes unacceptable.

It is thus necessary to find a way to perform environmental assessments of complex industrial systems with limited resources at an acceptable quality level. That is why this paper proposes an adapted eco-design project management methodology for complex industrial systems. This two-stage iterative methodology is based on a global environmental assessment of the system with a Lean Six Sigma approach, along with specific environmental improvement projects. This methodology naturally finds its place among the different environmental standards (in particular ISO 14006 [5], ISO 14062 [6] and ISO 14040 [7]) and methodologies proposed in the past, like ProductOriented Environmental Management Systems (POEMS, see [8]). Its main force is its compatibility with these standards, while being adaptable to company constraints; it allows adapting the study to the complexity of the system, thanks to a precise project charter.

The application of the first steps of the methodology was performed on an Alstom Grid AC to DC conversion substation for the aluminium industry. This industrial system is characterised by a high level of complexity in terms

\footnotetext{
${ }^{*}$ Contact author : Tel: +33141131328

Fax: +33141131272

E-mail: francois.cluzel@ecp.fr
} 
of the number of components and life cycle. Its environmental impacts are extremely dependent on the implantation context and the choices made at the super system level (aluminium smelter). Thus, this is a good example of a complex industrial system.

The results of this first LCA have provided with limited resources a strong basis to deploy eco-design activities. They have also permitted the establishment of a working group to orient the future eco-design activities within the company. The application of these next steps will ensure the ability of the methodology to successfully design and configure complex industrial systems from an environmental perspective.

The original methodology has undergone major improvements since its first version (see [9]) to permit its application in accordance to the company's constraints. This paper includes the last evolutions and applicative steps, as well as a clear positioning among the standards and other existing approaches.

Section 2 presents a definition of a complex industrial system and highlights the limits of eco-design and Life Cycle Assessments for such systems. This permits a clear positioning of the methodology among the different standards and previous approaches. The methodology is then detailed in Section 3 through the description of the different DMAIC steps. Section 4 proposes an application on Alstom Grid AC/DC conversion substations, with a focus on the main LCA results obtained thanks to the methodology. It shows the importance of focussing the improvement projects on particular aspects (life cycle phase, subsystem, component or material) while always considering a global environmental vision of the system. Finally, some conclusions and perspectives are given, the next applicative steps are described and the concept of an 'environmental configurator' is introduced.

\section{Methodological Positioning}

\subsection{Context of the Study}

This paper focuses on complex industrial systems whose specificities have not really been taken into account by eco-design and Life Cycle Assessment: these are industrial systems where complexity induces major issues in terms of modelling, prediction or configuration. If we consider the systems engineering domain, Blanchard and Fabricky [10] characterise engineered systems as systems that achieve operational objectives; that operate over a complete life cycle; that are composed of a combination of resources (humans, materials, equipment, money...); that are composed of subsystems and components that interact with each other; that are influenced by external factors from large systems and in interaction with the natural world. Adding an environmental dimension, we define a complex industrial system in the sense of eco-design as:

- A large-scale system in terms of subsystems and components, mass and resource usage

- A system whose life cycle is hardly predictable at the design level in the long-term, in particular its lifetime, upgrades, maintenance and end-of-life

- A system whose subsystems may have different life cycles and different obsolescence times

- A system in close interaction with its environment (super system, geographic site...)

- A system supervised by human decisions and management

Examples of such systems are, in particular, energy systems like the Alstom Grid conversion substations described in Section 4. In such systems, the classical eco-design limitations are amplified by the internal system complexity. In addition, complementary issues appear. These limitations are explained in more detail in the next sections.

\subsection{Limits of Eco-Design for Complex Industrial Systems}

From this definition, this part first considers LCA limits encountered in complex industrial systems. Then, wider eco-design limits are detailed to introduce the requirement definitions.

\subsubsection{Technical LCA Limits}

Life Cycle Assessments of large-scale energy systems have already been performed (see for example [11,12]). However, they are considered as 'classical' products. Local implantation in particular, due to the nature of electricity, seems crucial to approximate the real environmental impacts of these systems.

Moreover, the current eco-design limits, in particular for LCA are a recurrent discussion topic. Reap [13,14] gave a list of LCA problems by phase (see Table 1). The problems that particularly concern us in this paper are in bold in Table 1.

The boundary selection is hard to manage for complex industrial systems because the high number of subsystems and the interactions with surrounding systems make the boundaries fuzzy. Another problem concerns the inventory data granularity to choose, and more globally the data availability and quality [15]. Is it necessary to consider every 
screw or electrical component to obtain significant LCA results? This problem is also taken into account by Leroy, who highlights the need for quantified data [16].

The last problems raised by Reap that interest us, deal with the spatial dimensions, that means the variability that could exist for the same product on different geographical sites. Actually as it will be shown later in the paper, exogenous parameters such as electricity mix can have strong influences on the environmental impacts. We clearly need to manage the uncertainties about spatial dimensions to obtain significant results.

These technical problems are well known to LCA practitioners. We do not pretend to solve them, but we are looking for a methodology that will help us to consider them systematically.

Table 1. LCA problems by phase (from [13])

\begin{tabular}{lll}
\hline \multicolumn{1}{c}{ Phase } & \multicolumn{1}{c}{ Problem } \\
\hline $\begin{array}{l}\text { Goal and scope } \\
\text { definition }\end{array}$ & - Functional unit definition \\
& - Boundary selection \\
& - Alternative scenario considerations \\
\hline $\begin{array}{l}\text { Life cycle } \\
\text { inventory analysis }\end{array}$ & - Allocation \\
& - criteria \\
& Local technical uniqueness \\
\hline $\begin{array}{l}\text { Life cycle impact } \\
\text { assessment }\end{array}$ & - Impact category and methodology \\
& - Selection \\
& - Spatial variation \\
& - Docal environmental uniqueness \\
& - Time horizons \\
\hline $\begin{array}{l}\text { Life cycle } \\
\text { interpretation }\end{array}$ & - Weighting and valuation \\
\hline All & - Dncertainty in the decision process \\
\hline
\end{tabular}

\subsubsection{Overall LCA and Eco-Design Limits}

Apart from technical limits, other problems of the eco-design process management will be considered in our study. The first one is that LCA is an evaluation tool and not an improvement tool. It is then only the first stage of an ecodesign process. Dewulf shows in [17] that LCA is able to feed environmental improvement tools, but it needs to be based on an existing product. It is not adapted to a new product design [18].

Furthermore, ISO 14062 [6] specifies the need for a multi-disciplinary team throughout the eco-design process, but it does not specify how to build the team. The eco-design process is globally defined, but no standardised or systematic deliverables and milestones exist. As shown in the next section, the existing standards and methods stay at a requirement or guidelines level. To complete them an operational level seems necessary to manage the complexity of complex industrial systems.

Finally, there is no clear way to include the customer requirements that will orient the decisions throughout the process within the study.

\subsubsection{Methodology Requirements}

Following from the above, we need to define an operational methodology that:

- Can systematically consider the technical LCA limits concerning complex industrial systems

- Can be applied on different systems and subsystem levels

- Considers a reference product to improve

- Supports ISO standards for LCA

- Covers both the environmental evaluation and improvement phases

- Offers a rigorous framework with precise milestones and deliverables and a clearly defined team 
- Can take into account customer requirements

The next section studies the pre-existing approaches in the literature to refine and position the methodology detailed in Section 3.

\subsection{Literature Study}

\subsubsection{Normative Aspects}

The normative framework concerning environmental management and eco-design is constantly evolving. However, standards often stay at a high level of abstraction and are often difficult to apply directly in companies. We distinguish three normative levels in Figure 1. The requirements define the scope, the objectives and the global outline of the approach. The guidelines are more precise and propose general ways to attain the requirements. Finally, the operational methodologies, based on the guidelines, are directly applicable to the studied object. These three levels are represented on the $\mathrm{Y}$-axis. The $\mathrm{X}$-axis distinguishes the site-oriented approaches from the productoriented approaches. This distinction can also be made between site management and product design. The frames inside the diagram give a third dimension. The focus is on environmental management, and more precisely, ecodesign.

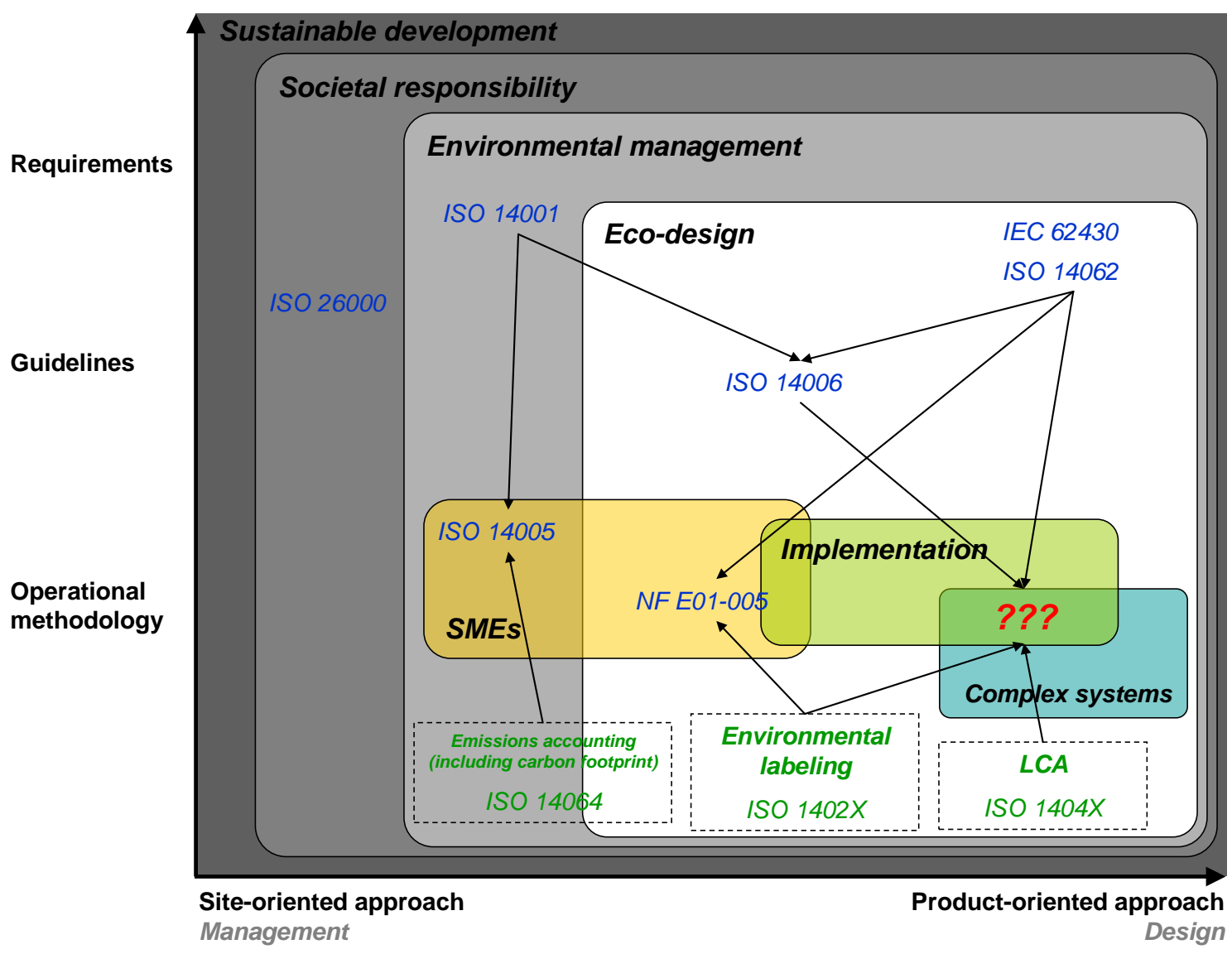

Figure 1. Positioning amongst some pre-existing environmental standards. The arrows represent the connections between the standards.

ISO 14062 [6] and IEC 62430 [19] standards are directly connected to eco-design by describing the main lines of the integration of the environment into product design. ISO 14006 [5] gives guidelines to incorporate eco-design into the more general framework of environmental management systems (ISO 14001 [20]). NF E01-005 [21] (French standard) caters to eco-design in small and medium enterprises with an operational, but simplified approach. Finally, ISO 14005 [22] permits the easy application of environmental management practices (from ISO 14001) in SMEs, but it is not focused on eco-design.

On the other hand, environmental tools like emissions accounting (ISO 14064 [23]), environmental labelling (ISO 
14020 series [24-27]), or Life Cycle Assessment (ISO 14040 series [7,28]) are clearly operational but only support a part of the eco-design process deployment.

Therefore, this diagram highlights the lack of an operational eco-design methodology for complex industrial systems based on well-established standards and supported by well-known environmental tools such as LCA. In these systems, the implementation stage is a real challenge and it has to be 'precaution' driven. This is why the issue is also highlighted in the diagram.

Now that the proposed methodology is precisely positioned amongst the different environmental standards, in the next section we can focus on the multiple approaches that exist in the literature.

\subsubsection{Product-Oriented Environmental Management Systems}

Due to this lack of operational standards to support a complete eco-design process in companies, different approaches have been proposed in the past, under the acronym POEMS (Product-Oriented Environmental Management Systems). They are mainly based on the fact that the classical EMS proposed in ISO 14001 are focused on site environmental aspects and they do not easily consider environmental impacts of products. The CALCAS report (Co-ordination Action for innovation in Life Cycle Analysis for Sustainability: a project financed by the Sixth Framework Programme of the European Commission) states that "traditional EMSs (ISO 14001, EMAS) do not encompass products in their procedures and do not answer to the needs of firms to communicate the environmental quality of products" [8]. Moreover, classical approaches often display major weaknesses in the management aspects of eco-design [8]. Finally, a common definition of POEMS appeared recently: a POEMS is defined as "an EMS with a special focus on the continuous improvement of a product's eco-efficiency (ecological and economic) along the life cycle, through the systematic integration of eco-design in the company's strategies and practices" [8,29-31].

Examples of POEMS are given in $[29,30,32,33]$. While these methodologies stay closely connected to academic works, other approaches, at Airbus for example [34], have been developed in major industrial companies. This particularly highlights the requirements of companies, namely to adapt POEMS to their own organisations [35]. This is mandatory to drive proactive eco-design activities successfully.

From the previous section, a comparison can easily be made between POEMS and ISO 14006, as these approaches aim at adapting EMS for eco-design. However, we consider that they stay at a guideline level, because they encompass all the eco-design activities of the company, starting at the environmental policy level. With a perspective of application to complex industrial systems, a methodological layer is clearly missing.

Moreover an analogy is made in [36] between POEMS and TQM (Total Quality Management). This comparison with the fields of quality and continuous improvement is extremely interesting and will be explored in the next sections. Actually, the rigor, the organisational aspects and the adaptability of such methodologies appear promising for the application of eco-design to complex industrial systems in concrete terms.

\subsubsection{Lean \& Green}

Lean \& Green is a concept mixing Lean Six Sigma and environmental considerations in order to minimise the environmental impact of a product, service or process. It appeared in the last decade. Several companies or organisms propose variants on Lean \& Green approaches.

The US Environmental Protection Agency has used this term since 2000, in a document called The Lean and Green Supply Chain [37]. The EPA has gone further since then and now proposes a structured and well-detailed approach called Lean Manufacturing and the Environment [38]. Different interesting toolkits are available:

- Lean and Environment Toolkit [39], which is oriented towards the identification of the environmental wastes in a supply chain

- Lean and Energy Toolkit [40], whose aim is to identify energy losses in an industrial process to improve performance

Furthermore, for several years IBM has offered a consulting offer called Green Sigma. "This is a new solution offering, which merges IBM's deep expertise in Lean Six Sigma with other robust green initiatives, resources and intellectual capital across the company" [41]. The Green Sigma project is divided into five stages: define key performance indicators, establish metering, deploy carbon dashboard, optimise processes and control performance which is very close to the Six Sigma DMAIC approach (Define, Measure, Analyse, Improve, Control).

Other approaches based on the same principles are described in [42] and [43]. These two books show several industrial case studies of Lean \& Green approaches. As in the previous examples, these different Lean \& Green approaches have advantages (use of the rigorous Lean Six Sigma framework to optimise complex systems), but we consider that they stay site-oriented and are hardly applicable to products (we consider the whole product life cycle). They potentially offer powerful tools to assess the environmental quality of supply chains and organisations and, 
consequently, they are more oriented towards environmental management systems (see ISO 14001 [20]).

\subsection{Synthesis}

This literature study has shown that no existing methodology is really adapted to manage the eco-design of complex industrial systems. POEMS and ISO 14006 offer a promising methodological layer, but they are not easily applicable at an operational level. This could be deliberate in order to let companies customise POEMS to their own organisation. However, the specificities of complex industrial systems in terms of eco-design make it necessary to develop an additional layer. Lean \& Green approaches are also useful to organisational aspects. That is why in the next section we will develop this additional layer on a DMAIC basis with close links to POEMS and ISO 14006.

\section{Model description}

The model proposed in this paper is based on two stages. The first is a "global approach" and is focused on environmental assessments and the identification of methods of improvement. The second includes several "specific approaches" and is more focussed on environmental improvements.

\subsection{General Model}

The main objective of the methodology is to permit an easier integration of eco-design in a company unit designing complex industrial systems, where there was no pre-existing approach. The focus is particularly on operational implementation throughout the organisation by giving a concrete and generic detailed process. It is more precise than POEMS and ISO 14006 that are focused on requirements and guidelines at a more strategic level. In the next section, we will present an application in a unit of Alstom Grid, where the strategic dimension of eco-design (environmental policy in particular) is pre-existing at the group level. The industrial needs are thus centred at the operational level in the unit. Therefore, the methodology is compatible with POEMS and ISO 14006 and complements them as a user-friendly layer.

A classical eco-design approach is divided into two main stages: environmental evaluation and environmental improvement. From an initial environmental assessment (often based on Life Cycle Assessment or simplified LCA), design recommendations emerge to improve the overall environmental performance of the product throughout its whole life cycle.

The proposed methodology maintains this global architecture, but the complexity highlighted in Section 2 makes the implementation of a classical eco-design process delicate. That is why the methodology is divided into a global environmental assessment on the one hand and specific improvement approaches on the other. It is designed to start from an expert approach (LCA) and evolve to an expert-assisted approach through a continuous rise in knowledge and competency and clearly defined deliverables. Figure 2 illustrates the iterative architecture of the methodology. This iterative nature ensures continuous improvement, a good capitalisation of the results as well as an effective expertise transmission. The next sections detail these different approaches.

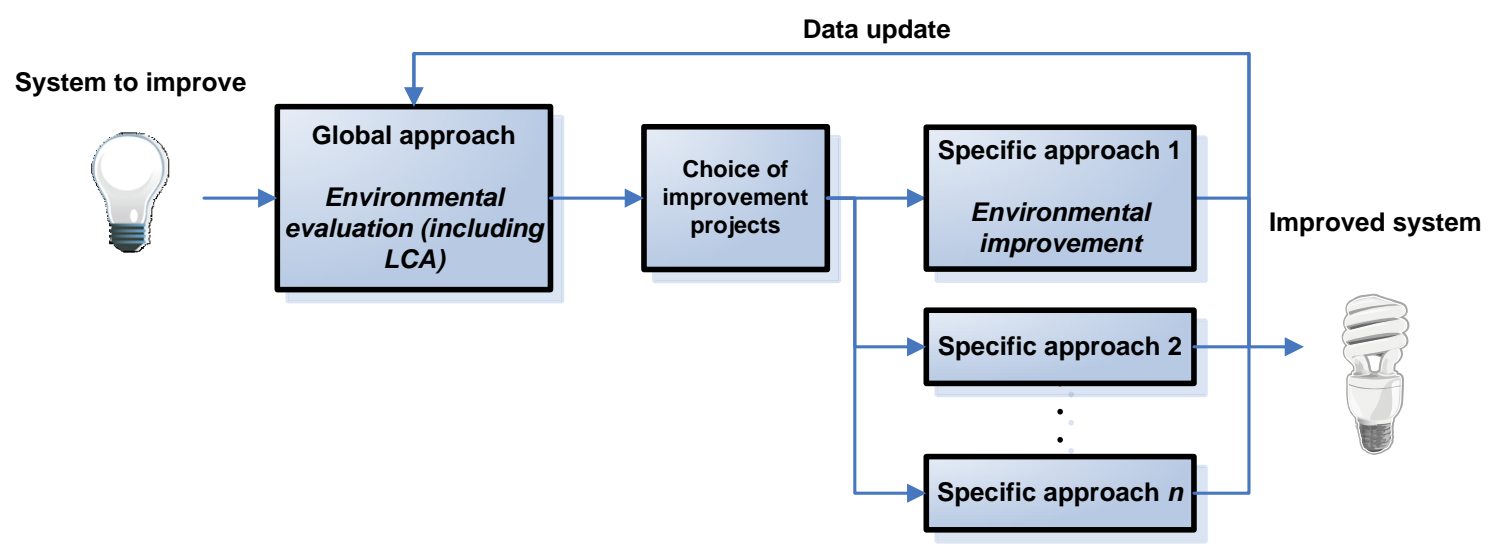

Figure 2. Global versus specific approaches to manage the eco-design of complex industrial systems

\subsection{About DMAIC}

In order to standardise and facilitate the deployment of this methodology in companies, it has been constructed on a 
Lean Six Sigma basis and, more precisely, on a DMAIC process. Lean Six Sigma is a continuous improvement approach, which gives competitive advantages and creates value for the stakeholders. Historically, increasing the performance of one dimension of the Quality, Cost, Time triangle meant decreasing the performance of the two other dimensions. In the continuous improvement paradigm (including Lean Six Sigma), all dimensions increase together. Lean Six Sigma is a mix of Lean Manufacturing and Six Sigma. Lean Manufacturing targets waste (waste increases costs and has no value for customers). It is a bottom-up approach. On the other hand, Six Sigma improves customer satisfaction by increasing quality and by killing variation. It is a top-down approach.

Lean Six Sigma includes two main methodologies: PDCA (Plan, Do, Check, Act, also known as the Deming wheel) and DMAIC (Define, Measure, Analyse, Improve, Control). Environmental management systems such as POEMS are based on PDCA [20] (see next section). They allow daily and continuous improvement. Contrary to the PDCA approach that increases performance thanks to successive iterations, the DMAIC approach offers an incremental performance improvement. It is based on a rigorous methodology that is adapted to complex problems whose nonsolution is known. A DMAIC project is supported by a multi-disciplinary team and a project leader, who is an expert in Lean Six Sigma. It lasts from four to six months and is formalised by precise deliverables. The DMAIC project is structured in five stages:

- Define: starts the project and formalises the problem. The main deliverables are a project charter, the voice of the customer and the team definition.

- Measure: identifies the problem reference base and collects the data needed to know the fundamental causes. The main deliverables are the definition and the identification of the key factors, process flow diagrams, and measuring system analysis.

- Analyse: the fundamental causes of the project are identified, representing the $20 \%$ of causes that produce $80 \%$ of the effects. The main deliverables are the identification of the potential causes, the estimation of the effects on the consequences and the validation of the causes and prioritisation.

- Improve: allows the definition, deployment and validation of the solutions. The main deliverables are the identification of innovative solutions, the validation of the solution impacts and the realisation of a pilot project.

- Control: aims to preserve the benefits and to standardise the solution throughout the company. The main deliverables are poka-yoke (fool-proofing), procedures, training, standardisation...

The methodology proposed in this paper is based on DMAIC. However, it is not an application of DMAIC to ecodesign, but an adaptation of DMAIC for the eco-design of complex industrial systems. The goal is to take advantage of the forces of DMAIC to make the process of eco-design for complex industrial systems more reliable, systematic and formalised.

\subsection{Integration in a POEMS or ISO 14006 Approach}

The good integration of this methodology in the POEMS or ISO 14006 approach is necessary. This issue is studied in this section.

Actually the POEMS approach, as well as the ISO 14006 approach are based on a PDCA cycle. The content of the four PDCA stages may change from one reference to another but it globally stays the same. From the previous POEMS references [8,29-36] and the ISO 14006 standard [5], it is possible to define the general processes linked to the PDCA stages (see Figure 3).

On Figure 3 the processes marked in bold represent the processes that are entirely managed by the proposed methodology, whereas the processes marked in italic are partially managed. The proposed methodology thus offered a concrete answer to the operational eco-design actions of a POEMS approach. The following sections will explain this methodology in more details. 




\begin{tabular}{|l|}
\multicolumn{1}{|c|}{$\mathbf{A C T}$} \\
- Spreading of the new products \\
- External communication \\
- Standardization \\
- Identification of new opportunities \\
(link with a new PDCA process)
\end{tabular}

\section{DO}

- Definition of roles and responsibilities

- Training and knowledge management

- Definition of eco-design procedures

- Development of eco-innovative products

- Documentation and internal

communication
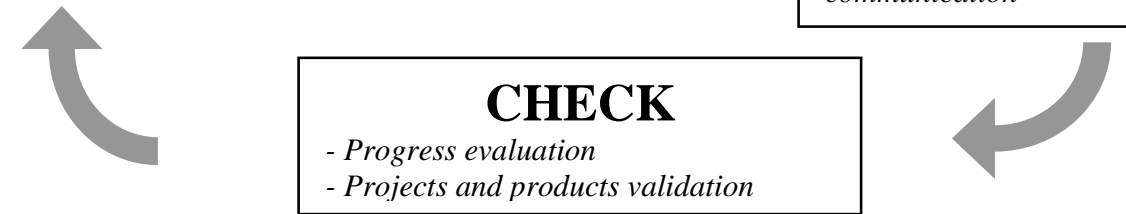

Figure 3. Generic POEMS approach

\subsection{Global Approach}

The global approach is devoted to a global environmental assessment of the system and to the identification of ways to improve this overall environmental performance. It gives concrete actions for the two PLAN processes in bold on Figure 3. It is implemented via an adapted DMAIC approach from the Six Sigma theory:

- Define: via a project charter, including the goal and scope phase of LCA, the objectives, the team and sponsors, the project plan and the impacts of the project are stated. The project charter is presented in Table 2 below. It includes the information required by ISO 14040 [7] at the Goal and Scope stage. This charter is a fundamental document to structure the project, as it clarifies all that is often implied in classical projects. Moreover, as it is compatible with LCA standards, it is a useful tool to ensure the validity and the communication of the project.

- Measure: this stage includes the Life Cycle Inventory (LCI) and the Life Cycle Impact Assessment (LCIA) phases of LCA. These two stages provide the data needed to identify the fundamental causes of the problem. During the Life Cycle Inventory, data is collected to model the system life cycle in the LCA software (mass, materials, energy, manufacturing processes, transport...). The potential environmental impacts associated with this life cycle are then calculated during the LCIA phase thanks to dedicated methods in the LCA software.

- Analyse: this third stage includes the last LCA phase, the Life Cycle interpretation. Through an analysis of the previous phases, as well as sensitivity and uncertainty analysis, the main environmental impacts are identified.

- Improve: the objective of this stage is to identify technological solutions to the fundamental causes. It is performed through the setting up of an internal and multidisciplinary working group. Creativity sessions based on the eco-design strategy wheel (also known as the Brezet wheel) [44] ensure the identification of the improvement projects, as well as the evaluation of their technical and economical feasibility thanks to a dedicated evaluation process based on maturity scale (not detailed in this paper).

- Control: the project responsibility is then returned to the sponsors who are able to choose the best improvement projects that will lead in the specific approaches. The results of the whole DMAIC project are communicated and capitalised. 
Table 2. The new project charter in line with the ISO standards dedicated to LCA.

\begin{tabular}{|c|c|}
\hline $\begin{array}{l}\text { Business impact } \\
\text { The material and immaterial expected benefits } \\
\text { are listed, as well as the efforts needed to reach } \\
\text { these benefits. } \\
\text { For example, the expected benefits could be: } \\
\text { - Environment: decreasing the environmental } \\
\text { impact over the whole lifecycle } \\
\text { - Cost: decreasing the Life Cycle Cost (LCC) } \\
\text { - Quality: increasing the component quality } \\
\text { (Lifetime extension, maintenance needs } \\
\text { limitation, energy losses decreasing...) } \\
\text { - Time: extension of the product lifetime } \\
\text { These elements need to be precise and } \\
\text { quantified. }\end{array}$ & $\begin{array}{l}\text { Problem/opportunity statement } \\
\text { The environmental problem is described according to } \\
\text { the Five Ws (and one H) formalism. } \\
\text { An example applied to the electrical substations } \\
\text { studied in Section } 4 \text { could be: Alstom Grid PEM } \\
\text { (Who?) wishes to optimise the environmental impact } \\
\text { of its conversion substations (What?) during the } \\
\text { design process (When?). These substations are sold } \\
\text { worldwide to primary aluminium plants (Where?) to } \\
\text { convert energy from high voltage networks to energy } \\
\text { that is usable for aluminium electrolysis. The study } \\
\text { aims to minimise the environmental impacts } \\
\text { throughout the product life cycle while still } \\
\text { considering the technical and economic criterion } \\
\text { (How?). It is a way for Alstom Grid PEM to be } \\
\text { differentiated from the competitors (Why?). }\end{array}$ \\
\hline $\begin{array}{l}\text { Key metrics } \\
\text { The objectives are described according to ISO } \\
\text { 14040 [7]: } \\
\text { - Intended application } \\
\text { - Reasons for carrying out the study } \\
\text { - Intended audience } \\
\text { - Are the results intended to be used in public } \\
\text { comparative assertions? } \\
\text { The key indicators are the environmental } \\
\text { indicators chosen for the study according to the } \\
\text { objectives and the intended audience. Other } \\
\text { indicators can be considered, such as technical } \\
\text { or economical, or even social in a sustainable } \\
\text { development perspective. }\end{array}$ & $\begin{array}{l}\text { Project scope } \\
\text { The expected information asked by ISO } 14040 \text { to } \\
\text { define the scope of the study is [7]: } \\
\text { - Studied product system } \\
\text { - Functions of the product system } \\
\text { - Functional unit } \\
\text { - System boundary } \\
\text { - Allocation procedures } \\
\text { - Selected impact categories and impact assessment } \\
\text { - methodology } \\
\text { - Asta requirements } \\
\text { - Limitations } \\
\text { - Initial data quality requirements } \\
\text { - Type of critical review, if any } \\
\text { - Type and format of the report }\end{array}$ \\
\hline $\begin{array}{l}\text { Project plan } \\
\text { The project milestones are defined. Each phase } \\
\text { duration needs to be detailed. }\end{array}$ & $\begin{array}{l}\text { Team selection } \\
\text { The members of the eco-design team are selected. } \\
\text { The different roles are: } \\
\text { - Sponsors, who ask for the project } \\
\text { - Champion, who vouches for the rigorous } \\
\text { application of the methodology } \\
\text { - Project leader (Black belt in a classical Lean Six } \\
\text { Sigma approach), who is responsible for the } \\
\text { progress of the project } \\
\text { - Team members, who are the human resources } \\
\text { allocated to the project }\end{array}$ \\
\hline
\end{tabular}

\subsection{Specific Approaches and Closed Loop}

Then the specific approaches allow the realisation of projects that have been chosen by the decision makers during the Control phase of the first DMAIC. These improvement projects are defined as classical R\&D projects of the companies with an added environmental follow-up at the different gate reviews. It answers to the DO and CHECK processes highlighted on Figure 3. 
The aim of such specific approaches is to classify the main and complex problems into sub-problems with a more precise scope and lower complexity. The specific approaches are designed to give the company a high level of freedom to adapt the environmental considerations to its processes. The idea is not to bring a new design constraint, but to consider the environment as a new opportunity to improve products and processes, to improve the brand image and finally to be differentiated from competitors.

In terms of implementation, a DMAIC approach also seems adapted to these projects. Nevertheless, it has to be differently adapted. Its objective is not to support the full project, but to ensure an environmental follow-up for the classical R\&D projects of the company. The five stages are:

- Define: a new project charter is defined based on the same model as Table 2. The difference with the global approach mainly concerns the scope and the objectives of the project.

- Measure: the LCI and LCIA stages are extended according to the project charter (the focus is on the subsystem or life cycle phase targeted by the project objectives).

- Analyse: the LCA results are analysed. Sensitivity and uncertainty analyses are sometimes performed.

- Improve: the new technical solution is developed in detail. A comparative LCA identifies its environmental benefits (and the potential impact transfers). Economic and technical aspects are also considered.

- Control: the project responsibility is returned to the sponsors, who are able to include the new technical solutions in the commercial offer. The results of the whole DMAIC project are communicated and capitalised. The sponsors can also plan further works, or launch a new global approach by updating the previous one.

Once the specific approaches have been performed (after several months or years, depending on the considered system), a new iteration of the entire process may be launched. The global approach would then be implemented on the new and environmentally optimised system. This ensures a continuous improvement process, taking into account potential evolutions of the system's environmental performance.

The next section proposes an application of the first stage of the methodology (global approach) within a business unit of Alstom Grid.

\section{Application of the Global Approach to Alstom Grid AC/DC Conversion Substations for the Aluminium Industry}

The conversion substations are briefly described, then an application of the global approach is detailed, as well as perspectives for the specific approaches.

\subsection{AC/DC Conversion Substations}

Alstom Grid PEM (Power Electronics Massy) designs, assembles and sells substations for the electrolysis of aluminium worldwide. These are electrical stations designed to convert energy from the high voltage network to energy that can be used for aluminium electrolysis, which is a particularly environmentally impacting and energyconsuming activity [11]. An electrolysis substation represents thousands of tons of power electronics components and transformers, costing tens of millions of Euros.

It is made up of several groups (four in Figure 4) that are composed of a regulating transformer, a rectifier transformer and a rectifier. The groups are connected on one side to the high voltage network through an electrical substation and on the other side to a busbar that is directly connected to the electrolysis potline. All the groups are supervised by control elements that are connected to the electrolysis pots to regulate the process. The amount of energy consumed by a recent primary aluminium plant is comparable to the amount of energy delivered by a nuclear plant unit (more than $1 \mathrm{GW}$ ).

In this context, Alstom Grid PEM wishes to minimise the environmental impacts of its products to answer to the environmental policy of the company and to be differentiated from competitors.

From the current substation's design, the objectives are to evaluate the environmental impacts throughout the product life cycle and to identify design parameters/impacting factors whose variation could minimise the environmental impact, while preserving the other design aspects. It will permit to identify and conduct environmental improvement projects. Finally, the results need to be reusable in the future The substations are considered to be complex industrial systems because:

- The number of subsystems and components is considerable. Some subsystems could themselves be considered as complex industrial systems (like transformers or rectifiers)

- The lifetime of a substation is really long, up to 35 or 40 years. Many uncertainties exist for the use and 
end-of-life phases. No end-of-life scenario is clearly known

- The substation is only a part of the aluminium plant. Their processes are closely connected and interdependent

- No standard design exists: the substation is tailor-made for each customer, even though the general design is often the same. We consider substations as a product family.

It is easy to understand that the complexity of the considered system makes the study delicate. The next section details how the global approach has been applied to an example of a substation.

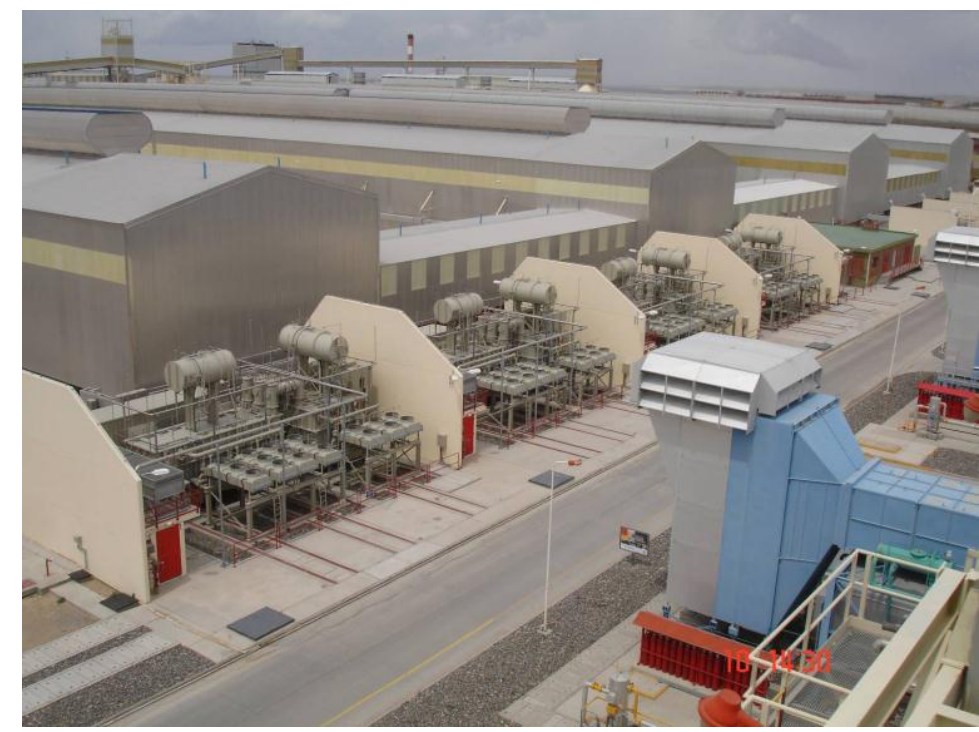

Figure 4. Example of an Alstom Grid AC/DC conversion substation (Aluar, Argentina)

\subsection{The DMAIC Process Including LCA}

\subsubsection{Define}

First the project charter was defined by following the template presented in Table 2 . The main objective of the study is the identification of the main environmental impacts of a substation in order to identify projects to improve its environmental performance. Therefore, its purpose is to orient future eco-design activities at Alstom Grid PEM.

The study is focused on an Alstom Grid AC/DC conversion substation that has been designed and is currently under construction for the Hindalco Mahan aluminium smelter. The whole life cycle of the substation will be considered. The Hindalco Mahan aluminium smelter (under construction too) is located in central India (Bargawan, state of Madhya Pradesh). It is characterised by a captive coal power plant (900 MW) and is designed to produce 360,000 tons of primary aluminium per year with modern electrolysis pots.

Considering the constraints and characteristics of such a project, the following functional unit is considered: "To ensure the conversion of $220 \mathrm{kV}_{A C}$ high voltage energy to energy usable for aluminium electrolysis ( $360 \mathrm{kA} \mathrm{A}_{D C}, 1650$ $\left.V_{D C}\right)$ according to the Hindalco specifications for 30 years, without interruption". This functional unit is adapted to our needs, namely to feed internal eco-design works on substations. The substation lifetime is 30 years, which means that the reference flow is 1 .

The substation is broken down into eight subsystems: regulating transformers, rectifier transformers, rectifiers, busbars, filters, control, civil engineering, and other equipment. Each of these subsystems is itself divided into subassemblies and hundreds of components.

Data granularity, that means the extent to which the system is broken down into small parts, is chosen to permit the identification of the main environmental impacts on the whole substation life cycle, without spending too much time in collecting the data. Limitations and weaknesses of the study are rigorously documented to facilitate the analysis and ensure the quality of future works. This means that a compromise has been found between the durations of the study and the quality of the results. By highlighting these constraints, the project charter has permitted to quickly define the data granularity and to make acceptable some simplifications as this LCA is performed for internal used only.

The system is modelled using SimaPro 7.2 software. As well as the specific data from Alstom Grid, the LCI data 
comes from Ecoinvent V2.1 database [45]. The LCIA results are calculated with the ReCiPe 2008 midpoint $(\mathrm{H})$ V1.03 methodology [46]. Data inventory and data quality are managed thanks to a procedure based on [15].

Concerning the organisational aspects, the three first phases of the study were planned in five months. About one month was necessary to structure the project and define the scope and objectives (Define), four months to collect the data (Measure), and one month to collect and analyse the LCIA results (Measure/Analyse). Considering the size and the complexity of the system, this particularly satisfactory. The two last phases (Improve and Control) are not detailed.

\subsubsection{Measure}

Flow charts were built from a SIPOC analysis of each substation subsystem. SIPOC is a Six Sigma tool to identify the Suppliers, Inputs, Processes, Outputs and Customers of an industrial object. These analyses ensure the coverage of the life cycle of the substation. Different data sources were used:

- Internal Alstom Grid data

- Data from suppliers, subcontractors or other units

- Generic data (from LCA databases or literature)

Specific data was collected in a large predefined Excel sheet. It mainly concerns the following elements: masses, distribution, energy consumptions and end-of-life. Materials extraction and production, energy production and distribution, as well as other data, are generic.

The potential environmental impacts of the substations were calculated with the ReCiPe 2008 method [46]. About 35 simulations were conducted with different substation breakdowns (by life cycle phases, by subsystems). Moreover, three other electrical mixes were considered in addition to the coal mix effectively used at the Hindalco Mahan smelter as a way to easily manage the geographical dimension of the substation site: natural gas, hydro and nuclear.

\subsubsection{Analyse}

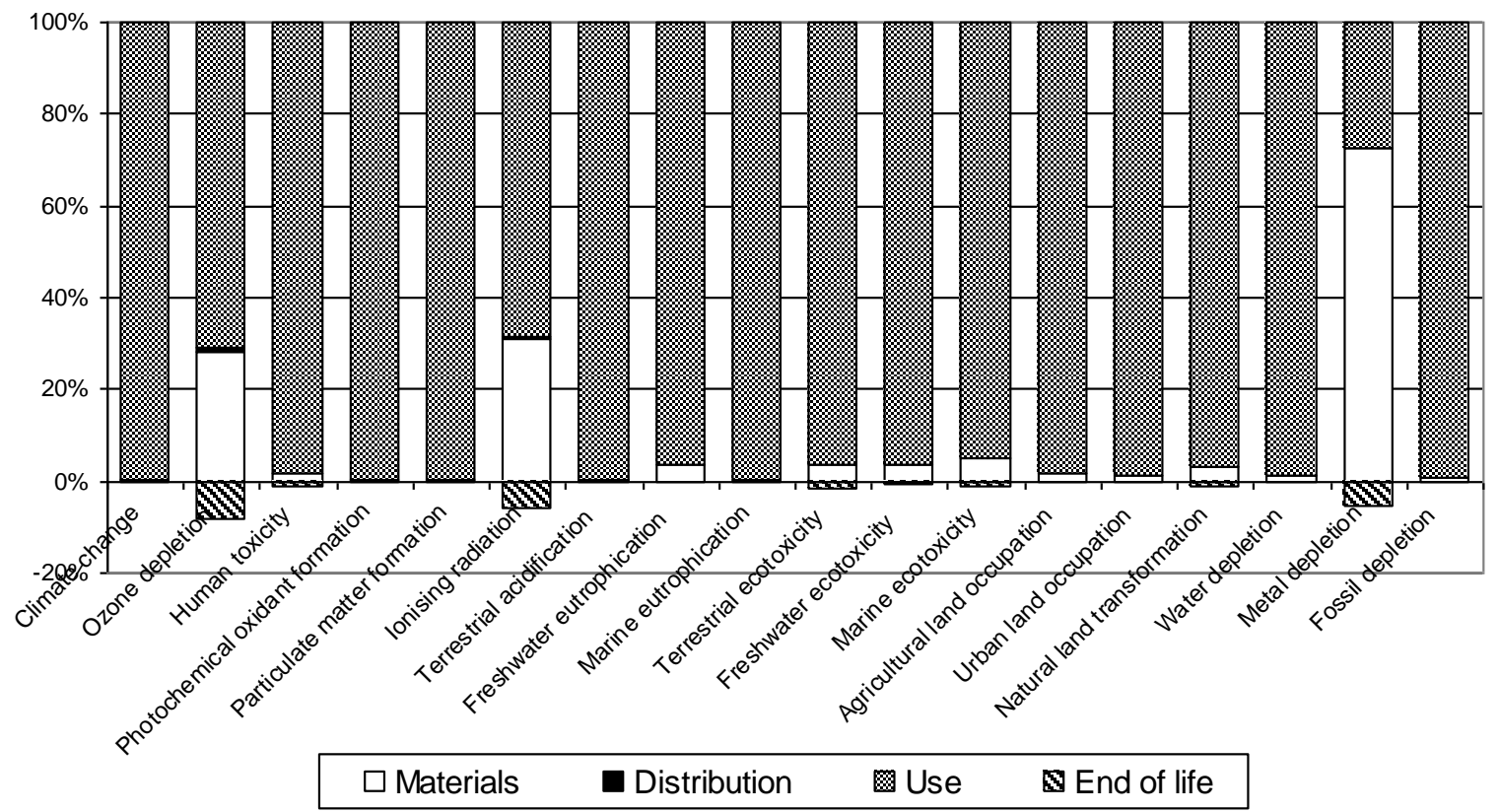

Figure 5. Breakdown by life cycle phases of the substation life cycle impacts

More details on the LCA results are given in [47]. We will only draw the main conclusions in this section.

Figure 5 gives an overview of the potential environmental impacts of the substation's whole life cycle, with a breakdown by life cycle phases. It appears that the use phase is responsible for more than $95 \%$ of the total impacts, except for three impact categories: ozone depletion, ionising radiation, metal depletion. For these categories, the contribution of the materials phase is higher. This is mainly due to metal production (steel, copper, aluminium).

The domination of the use phase is clearly due to the production of electricity from coal, which is particularly impacting. Figure 5 also shows that the distribution phase is almost negligible. The end-of-life phase allows to 
reduce the impacts by a further $10 \%$ (see small bars below the horizontal axis) of the total impacts.

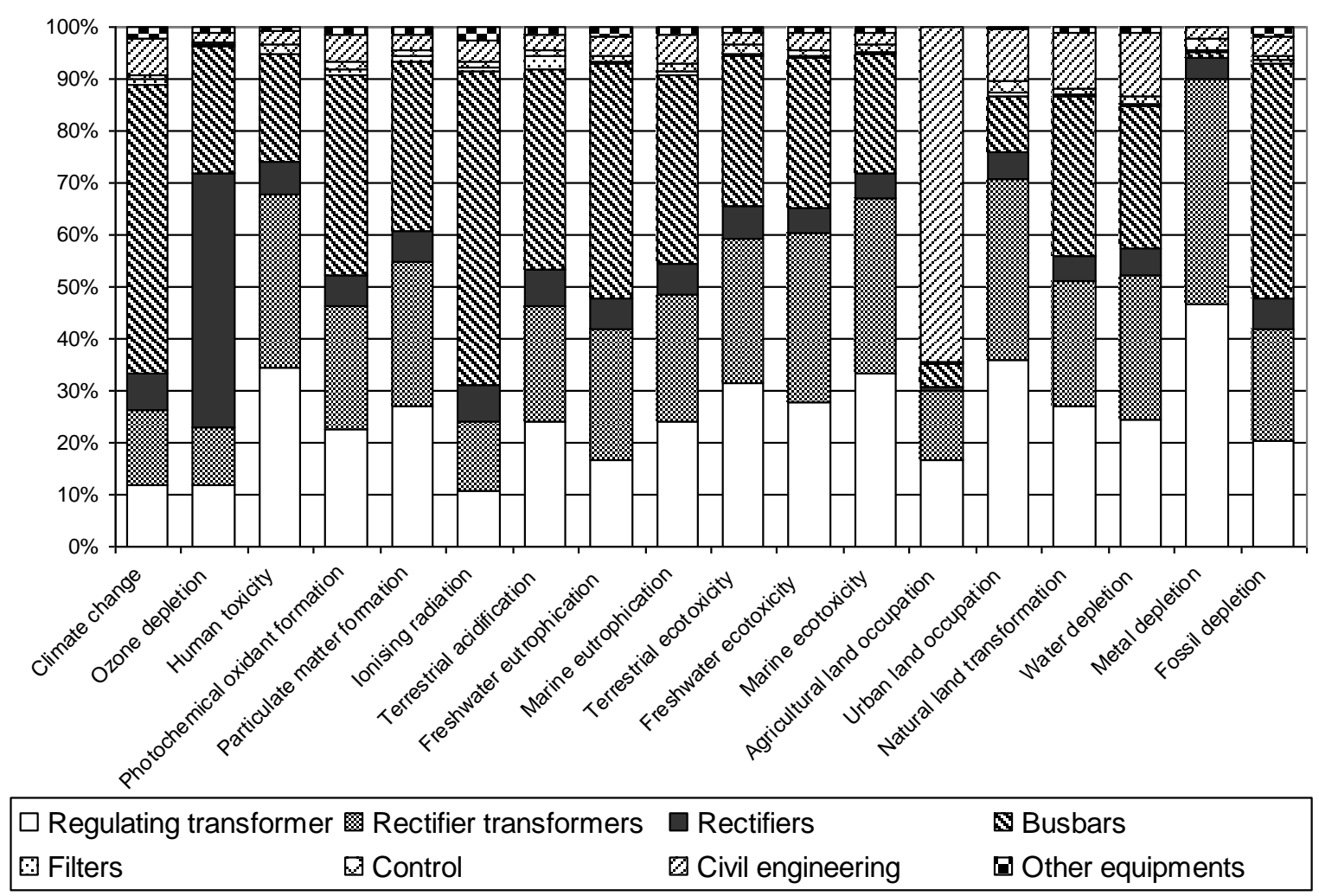

Figure 6. Breakdown by subsystems of the materials phase impacts

Figure 6 presents the breakdown by subsystem of the impacts associated with the materials phase. The busbars (550 tons of primary aluminium) and the regulating and rectifier transformers are the most impacting subsystems. However, three impact categories present singular results: ozone depletion, agricultural land occupation and metal depletion. These are explained by the use of some materials, like PTFE or concrete. The total impact generated by the transformers, rectifiers, busbars and civil engineering reaches more than $95 \%$ of the total impacts of the materials phase. The other subsystems (filters, control and other equipment) have negligible impacts.

As the electricity used by these subsystems comes from the same source (a coal power plant), the contribution of the subsystems in the use phase is the same for every impact category and corresponds to their contribution to the electrical losses. Thus, the electrical losses of the rectifiers and transformers represent about $89 \%$ of the total losses. The most impacting subsystem is the rectifier transformer, with $40 \%$ of the impacts.

Finally, Figure 7 shows the comparison of the environmental impacts for the four electricity sources. $100 \%$ represents the highest value among the four levels. If the hydro scenario is clearly the best alternative, it is more difficult to separate the three other scenarios. For example, the nuclear scenario is the worst one in ionising radiation and (only just) in metal depletion. The coal scenario reaches the highest values for the other categories. The comparison between the breakdown by life cycle phases for the hydro scenario and the coal scenario (the two "extreme" scenarios) gives the most interesting results. It appears that the contribution of the use phase has largely decreased in the hydro scenario. This means that the materials phase is now responsible for more than $50 \%$ of the total life cycle impacts in most of the impact categories. This is an extremely important result, which shows that the eco-design activities or the configuration choice stemming from the analysis of these environmental profiles may be different from one substation to another. Actually, in the Hindalco Mahan case (electricity from coal), the lowering of the electrical losses is the best way to improve the overall environmental performance of the substation. Impact transfers from the use phase to the materials phase may be acceptable if the environmental benefits are significant. On the other hand, in a Canadian case (hydroelectricity), minimising weights and substituting materials can bring significant benefits.

All these conclusions were documented in a full internal LCA report. They constitute a strong basis to feed the Improve phase. 


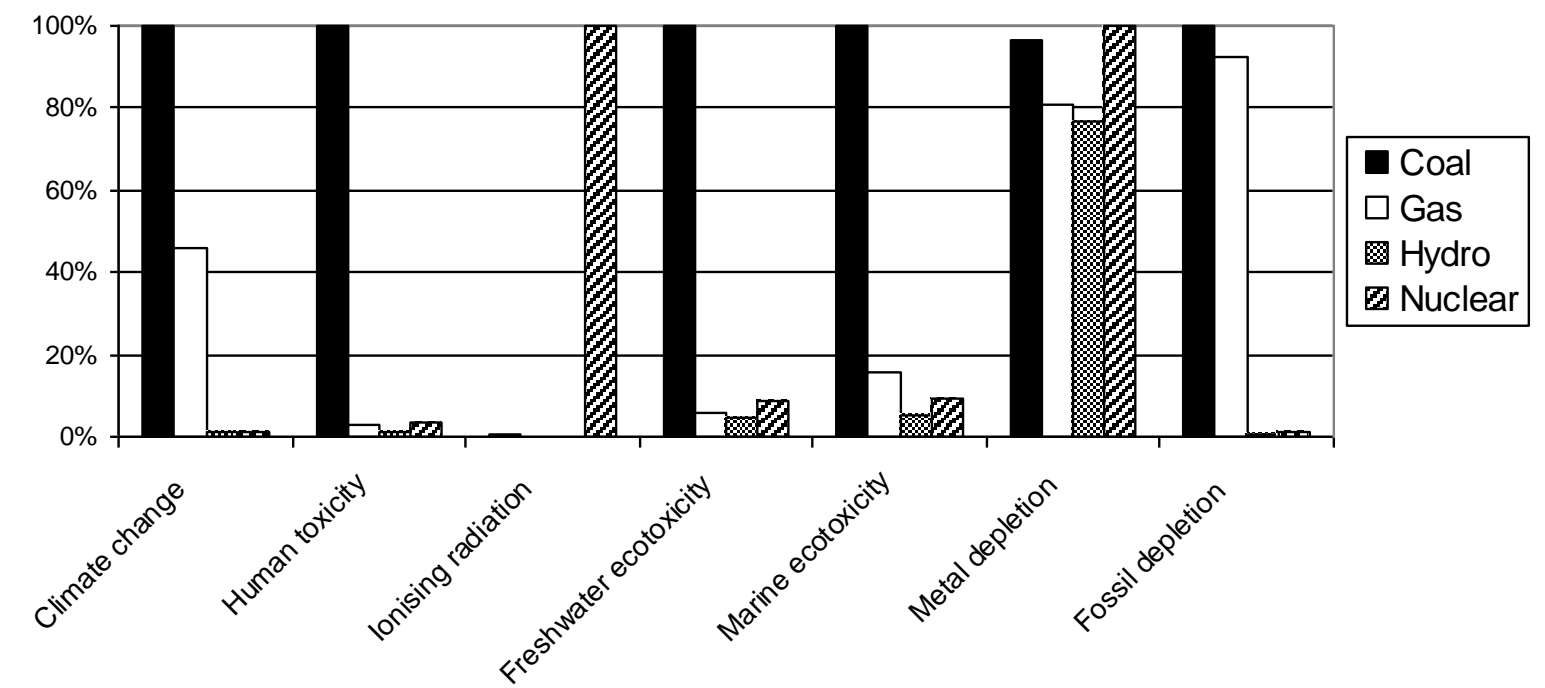

Figure 7. Comparison of four electricity sources scenarios for the whole substation life cycle. Only seven impact categories (in normalised results) are represented.

\subsubsection{Improve}

The LCA results described in the previous part offered promising improvement methods to optimise the environmental performance of the substation, but it is clearly necessary to define them and to consider their technical and economic aspects. This knowledge is not owned by the eco-design experts, but by the substation designers. That is why the Improve phase was conducted via a working group and creativity sessions.

Using the eco-design strategy wheel (also known as the Brezet wheel [44]), the working group generated in two hours more than 100 improvement ideas, identified the 16 most powerful improvement projects, that means the best compromises between environmental performance improvement, technical feasibility and costs. 16 projects were selected and synthesised in predefined sheets (called "variant sheets"), and positioned thank to a dedicated assessment grid based on maturity scales and qualitative evaluations. Among these 16 projects, it was assumed that $50 \%$ would not have emerged without the creativity process deployed in the DMAIC framework.

\subsubsection{Control}

Once the Improve phase has been performed, the entire project has been be capitalised and precisely documented to be reusable in the future (for a new iteration of the global approach for example). Results have been communicated (internally and externally) and assigned a value. The responsibility of the project has now been given back to the sponsors (decision makers) who have chosen the improvement projects to perform in specific approaches. The general idea of this work is to build up a catalogue of eco-designed technological solutions. From a given context (country, electrical mix, customer specifications), it will be possible to define the best configuration of a substation from an environmental point of view.

\section{Perspectives and Conclusions}

In this paper, an adapted methodology has been presented to manage the eco-design of complex industrial systems. This methodology is based on a DMAIC approach and is integrated within the framework of ISO 14006 [5], ISO 14062 [6] and POEMS (Product-Oriented Environmental Management Systems [8]) as an operational layer. It is composed of two main stages (global approach/specific approaches), corresponding to the environmental assessment and improvement stages of a classical eco-design approach, and mainly answering to the PLAN and DO stages of a POEMS process. The global approach integrates Life Cycle Assessment to identify the potential environmental impacts of the full system. From a predefined project charter, the DMAIC process offers precise deliverables and milestones to make the process of eco-design for complex industrial systems more reliable. It permits in particular to plan in a short time and with limited resources an environmental assessment that is sufficient to feed an internal ecoinnovation process, by identifying a compromise between data availability, boundary selection and constraints in the company. Once the environmental impacts have been determined, a working group is set up to identify environmental improvement projects thanks to eco-innovation tools. The last phase of DMAIC assures the 
capitalisation of the benefits and offers the decision makers the ability to plan the realisation of the most promising improvement projects. These projects are performed via specific approaches, which are also based on a DMAIC process. However, these specific approaches are more focused on environmental improvement and technological solutions development. A specific approach only considers a small part of the initial system life cycle and the association of the different specific approaches ensures a significant improvement in the environmental performance of the system. Iterations of the whole process will ensure continuous improvement in the course of time and will steer the classical organisation towards becoming an eco-designing organisation.

The global approach has been successfully applied on Alstom Grid AC/DC conversion substations for the aluminium industry. The Define, Measure, and Analyse phases have given excellent results to feed the creativity sessions of the working group in the Improve phase. The LCA of a substation has allowed the identification of the main contributors to life cycle impacts, such as subsystems, life cycle phases or materials. The technical knowledge of the Alstom Grid designers has then offered significant ways to improve the overall substation's environmental performance.

On this basis, the decision makers at Alstom Grid PEM will be able to plan the most promising of the 16 improvement projects as R\&D projects. An environmental follow-up will also be provided to ensure the validity of the environmental benefits. The following process will be performed by complementing the classical R\&D project:

- At the initiation review stage: definition of the environmental objectives and scope, identification of simplified environmental indicators and associated targets to easily monitor the project's progress. Examples of such indicators are aluminium mass, electrical losses, transformer oil volume... these can easily be manipulated by people who are not experts in eco-design. This review matches the Define stage of DMAIC.

- The other gate reviews (not detailed here for confidentiality reasons) assess the progress. They are set all along the Measure, Analyse and Improve stages of DMAIC.

- The last gate review coincides with the end of the Control stage of DMAIC. It marks the end of the project. Following this process for different improvement projects will eventually generate a catalogue of eco-designed technical solutions available for future projects. After completing all the improvement projects (in maybe months or years, depending on the system), Alstom Grid PEM will be able to iterate the whole process by launching a new global approach.

Besides those organisational considerations on the eco-design of complex industrial systems, other more technical issues appear. This methodology actually offers the possibility of constituting a portfolio of eco-designed technological solutions, but it does not propose the best environmental configuration (best compromise between environmental impacts, costs, reliability according to the customer requirements) of a complex industrial system in a given context. For example, the best environmental configuration of a substation would not be the same if the electricity in the use phase is produced from coal or from hydropower. The main extension of this methodology now consists in developing simulation models based on design of experiments. From an implantation context, such a tool could identify the best parameters to design the substation. This concept is currently under way.

\section{Acknowledgments}

We gratefully thank Joël Devautour and François Puchar from Alstom GRID PEM for their full support in this work.

\section{References}

[1] European Union, 2003, Directive 2002/96/EC of the 27 January 2003 on waste electrical and electronic equipment (WEEE).

[2] European Union, 2003, Directive 2002/95/EC of the 27 January 2003 on the restriction of the use of certain hazardous substances in electrical and electronic equipment.

[3] European Union, 2005, Directive 2005/32/EC of 6 July 2005 establishing a framework for the setting of ecodesign requirements for energy-using products.

[4] European Union, 2006, Regulation (EC) $\mathrm{n}^{\circ}$ 1907/2006 of the European Parliament and of the Council of 18 December 2006 concerning the Registration, Evaluation, Authorisation and Restriction of Chemicals (REACH).

[5] International Organization for Standardization, 2011, ISO 14006:2011 - Environmental management systems - Guidelines for incorporating ecodesign.

[6] International Organization for Standardization, 2002, ISO/TR 14062:2002 - Environmental management Integrating environmental aspects into product design and development. 
[7] International Organization for Standardization, 2006, ISO 14040:2006 - Environmental management - Life cycle assessment - Principles and framework.

[8] Wuppertal Institute for Climate, Environment, Energy, 2008, D10 SWOT analysis of concepts, methods and models potentially supporting Life Cycle Analysis.

[9] Cluzel F., Yannou B., Afonso D., Leroy Y., Millet D., and Pareau D., 2010, "Managing the complexity of environmental assessments of complex industrial systems with a Lean 6 Sigma approach," Proc. CSDM 2010, Complex Systems Design and Management 2010, Paris, France.

[10] Blanchard B. S., and Fabrycky W. J., 2011, Systems engineering and analysis, Pearson Prentice Hall, Upper Saddle River N.J.

[11] Schmidt J., and Thrane M., 2009, "Life cycle assessment of aluminium production in new Alcoa smelter in Greenland."

[12] Macharey U., Schnettler A., and Smolka T., 2007, "Life Cycle Assessment of Ultra High Voltage system layout and operation compared to $420 \mathrm{kV}$ AC power systems," IEC/CIGRE UHV Symposium, Beijing, China.

[13] Reap J., Roman F., Duncan S., and Bras B., 2008, "A survey of unresolved problems in life cycle assessment - Part 1: goal and scope and inventory analysis," The International Journal of Life Cycle Assessment, 13(4), pp. 290-300.

[14] Reap J., Roman F., Duncan S., and Bras B., 2008, "A survey of unresolved problems in life cycle assessment - Part 2: impact assessment and interpretation," The International Journal of Life Cycle Assessment, 13(5), pp. 374-388.

[15] Weidema B. P., and Wesnæs M. S., 1996, "Data quality management for life cycle inventories--an example of using data quality indicators," Journal of Cleaner Production, 4(3-4), pp. 167-174.

[16] Leroy Y., 2009, "Development of a methodology to reliable environmental decision from Life Cycle Assessment based on analysis and management of inventory data uncertainty," PhD Thesis, Ecole Nationale Supérieure d'Arts et Métiers, Chambéry, France.

[17] Dewulf W., 2003, "A pro-active approach to ecodesign: framework and tools," PhD Thesis, Katholieke Universiteit Leuven.

[18] Millet D., Bistagnino L., Lanzavecchia C., Camous R., and Poldma T., 2007, "Does the potential of the use of LCA match the design team needs?," Journal of Cleaner Production, 15, pp. 335-346.

[19] International Electrotechnical Commission, 2009, IEC 62430:2009 - Environmentally conscious design for electrical and electronic products.

[20] International Organization for Standardization, 2004, ISO 14001:2004 - Environmental management systems - Requirements with guidance for use.

[21] Association Française de Normalisation, 2010, NF E01-005 - Produits mécaniques - Méthodologie d'écoconception.

[22] International Organization for Standardization, 2008, ISO/DIS 14005:2008 - Environmental management systems - Guidelines for the phased implementation of an environmental management system, including the use of environmental performance evaluation.

[23] International Organization for Standardization, 2006, ISO 14064:2006 - Greenhouse gases.

[24] International Organization for Standardization, 2000, ISO 14020:2000 - Environmental labels and declarations - General principles.

[25] International Organization for Standardization, 1999, ISO 14021:1999 - Environmental labels and declarations - Self-declared environmental claims (Type II environmental labelling).

[26] International Organization for Standardization, 1999, ISO 14024:1999 - Environmental labels and declarations - Type I environmental labelling - Principles and procedures.

[27] International Organization for Standardization, 2006, ISO 14025:2006 - Environmental labels and declarations - Type III environmental declarations - Principles and procedures.

[28] International Organization for Standardization, 2006, ISO 14044:2006 - Environmental management - Life cycle assessment - Requirements and guidelines.

[29] Rocha C., and Brezet H., 1999, "Product-oriented environmental management systems: a case study," The Journal of Sustainable Product Design, 10, pp. 30-42.

[30] Rocha C., and Silvester S., 2001, "Product-Oriented Environmental Management Systems (POEMS) - From Theory to Practice - Experiences in Europe," Proceedings of LCM2001, 1st International Conference on Life Cycle Management, Copenhagen, Denmark.

[31] Ammenberg J., and Sundin E., 2005, "Products in environmental management systems: drivers, barriers and experiences," Journal of Cleaner Production, 13(4), pp. 405-415. 
[32] Masoni P., Luciani R., Rinaldi C., and Zamagni A., 2007, "Implementation of a POEMS model in firms of the wood furniture sector," Proc. 3rd International Conference on Life Cycle Management, LCM2007, Zürich, Switzerland.

[33] van Berkel R., van Kampen M., and Kortman J., 1999, "Opportunities and constraints for Product-oriented Environmental Management Systems (P-EMS)," Journal of Cleaner Production, 7(6), pp. 447-455.

[34] Airbus, 2008, Site and Product Oriented Environmental Management System - SPOEMS - General presentation.

[35] de Bakker F. G. A., Fisscher O. A. M., and Brack A. J. P., 2002, "Organizing product-oriented environmental management from a firm's perspective," Journal of Cleaner Production, 10(5), pp. 455-464.

[36] de Bakker F. G. A., 2001, "Product-Oriented Environmental Management: Lessons from Total Quality Management," Journal of Industrial Ecology, 5(2), pp. 55-69.

[37] US Environmental Protection Agency, 2000, "The Lean and Green Supply Chain: a practical guide for materials managers and supply chain managers to reduce costs and improve environmental performance."

[38] US Environmental Protection Agency, 2009, "Lean Manufacturing and the Environment," http://www.epa.gov/lean/leanenvironment.htm.

[39] US Environmental Protection Agency, 2007, "The Lean and Environment Toolkit."

[40] US Environmental Protection Agency, 2007, "The Lean and Energy Toolkit."

[41] IBM, 2009, "Green Sigma - How to optimise your carbon management through Green Sigma."

[42] Olson E., 2010, Better green business - Handbook for environmentally responsible and profitable business practices, Wharton School Publishing, Upper Saddle River N.J.

[43] Association for Manufacturing Excellence, 2008, Green manufacturing - Case studies in Lean and Sustainability, Productivity Press, New York.

[44] Brezet H., and Van Hemel C., 1997, Ecodesign: A Promising Approach to Sustainable Production and Consumption, UNEP.

[45] Ecoinvent, 2007, "Overview and Methodology - Data v2.0 (2007)."

[46] Goedkoop M., Heijungs R., Huijbregts M., De Schryver A., Struijs J., and Van Zelm R., 2009, "ReCiPe 2008 - A life cycle impact assessment method which comprises harmonised category indicators at the midpoint and the endpoint level - First edition - Report I: Characterisation."

[47] Cluzel F., Millet D., Leroy Y., and Yannou B., 2010, "Relative contribution of a subsystem to the environmental impact of a complex system: application to aluminium electrolysis conversion substations," Proc. IDMME - Virtual Concept 2010, Bordeaux, France. 